\title{
Antiinflammatory effect of inhaled nitric oxide on acute lung injury
}

Younsuck Koh, M.D., PhD.

\begin{abstract}
Despite no reported survival benefit by inhaled nitric oxide (NO) among patients with acute respiratory distress syndrome (ARDS) until now, NO inhalation is still deemed acceptable as a rescue therapy for ARDS patients with refractory hypoxemia to various therapeutic measures. However, it is unclear whether inhaled NO exerts either detrimental or beneficial effects on the pathogenesis of ARDS. Laboratory studies suggest that inhaled NO might reduce some types of acute lung injury (ALI). By contrast, NO and nitrite could interact with neutrophil myeloperoxidase or high oxygen in the alveoli to stimulate oxidative reactions during inflammation. Recent experimental data suggest that inhaled NO might attenuate endotoxin-induced ALI. Considering the diverse role of NO as an important endogenous regulatory molecule on both proinflammatory and antiinflammatory processes, the effects of early and continued therapy with low dose of inhaled NO on ALI should be determined.
\end{abstract}

Key words: (1) ARDS, (2) NO inhalation, (3) pathogenesis, (4) antiinflammation

\section{Introduction}

Acute respiratory distress syndrome (ARDS) is characterized by permeability pulmonary edema induced by different kinds of inflammatory mediators. Many antiinflammatory therapeutic trials have failed in improving ARDS patients' outcome, although each trial has been founded on pathogenesis of acute lung injury (ALI). Recent researches on inflammatory responses have drawn more interest to cytokine signaling and transcriptional regulatory proteins.

Nitric oxide (NO), a ubiquitous mediator of cell-cell and intracellular communication, is a gaseous molecule containing an unpaired electron. NO is synthesized by aminoacid L-arginine by NO synthase (NOS) and released from various cells after chemical and mechanical activation. Up until now, three different NOS isoforms, including constitutive neuron NOS, constitutive endothelium NOS, and inducible NOS (iNOS) have been identified ${ }^{1)}$. Macrophages appear to be the principle cellular source of iNOS regulated by cytokines and endotoxin at the transcriptional level. There is evidence that $\mathrm{NO}$ is an important endogenous regulatory molecule implicated in both proinflammatory and antiinflammatory processes developing in lung ${ }^{2}$. Dual action of NO on endotoxin-induced microvascular plasma leakage in airway was reported. Bernareggi and colleagues suggest that endogenous NO seems to suppress plasma leakage under physiological condition, but when iNOS is expressed by endotoxin, the increased production of NO is likely to enhance plasma leakage ${ }^{3)}$. The aim of this review is to overview the effect of inhaled NO on the pathophysiology of ALI.

\section{Clinical Application of NO inhalation to ARDS patients}

Inhalational use of nitric oxide in patients with ARDS has been applied to decrease pulmonary hypertension and improve oxygenation. Since inhaled NO enters regions of the lung in proportion to local ventilation, selective vasodilation of the well-ventilated lung regions by NO diverts pulmonary artery blood flow to-

Division of Pulmonary and Critical Care Medicine, Departments of Internal Medicine, Asan Medical Center, University of Ulsan College of Medicine 388-1 Pungnap-dong, Songpa-gu, Seoul 138-736, Korea 
wards well-ventilated alveoli and often improves the matching of ventilation to perfusion. Limited half-life of $\mathrm{NO}$ in the circulation, in part, accounts for these selective pulmonary effects by inhaled $\mathrm{NO}^{4}$. $\mathrm{NO}$ is inactivated through the reaction with hemoglobin in red blood cells.

Its beneficial effect on oxygenation is reported to be less than $5 \mathrm{ppm}$ of inhaled NO and the maximum effect is about $10 \mathrm{ppm}$ among ARDS patients ${ }^{5)}$. NO-induced improvement in arterial oxygenation is positively influenced by the degree of alveolar recruitment ${ }^{6}$. When combined NO inhalation with prone positioning, the additive effect on the oxygenation and hemodynamics is observed among patients with severe

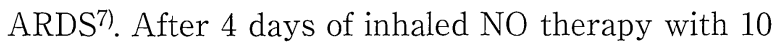
ppm among ARDS patients, the dose-response curve of NO showed a peak response at $1 \mathrm{ppm}^{5}$. This result demonstrates that long-term inhaled NO with constant dose can lead to the deterioration of oxygenation after several days, suggesting the daily dose adjustment of inhaled NO for better oxygenation among ARDS patients. The questions as to why the oxygenation worsens again at higher inhaled NO during continuous NO inhalation remains unanswered. Dellinger and colleagues report the effects of inhaled NO on the 28-day mortality rate of 177 patients with non-septic ARDS. They turned out to be unaffected by NO therapy in a multicenter phase 2 trial $^{8)}$. It is not recommended to use inhaled NO in patients with ARDS at now, although NO inhalation is still applied as a rescue therapy for ARDS patients, who show refractory hypoxemia with various therapeutic measures. Previous studies including the Dellinger's study ${ }^{8}$, they did not taper the inhaled NO during the continuous NO inhalation. That might influence on the no positive survivor benefit of NO inhalation. Low does of inhaled NO reduced the extent to which extracorporeal membrane oxygenation was needed in neonates with hypoxemic respiratory failure and pulmonary hypertension ${ }^{9}$.

\section{The Effect of NO inhalation on the pathogen- esis of ALI}

Recent studies suggest that NO is an important endogenous regulatory molecule and inhaled NO can alter the inflammatory response of ARDS. Inhaled NO seems to be implicated in both proinflammatory and antiinflammatory processes in lung. Laboratory studies show that inhaled NO has an important effect on reducing some types of lung and tissue injury. These effects include the ability to scavenge reactive oxygen species $(\mathrm{ROS})^{10)}$, and to reduce neutrophil function, retrieved from the alveolar spaces of ARDS patients, to generate $\mathrm{H}_{2} \mathrm{O}_{2}$ and to express $\beta_{2}$ integrin $\mathrm{CD} 11 \mathrm{~b} / \mathrm{CD} 18^{11)}$. Inhaled $\mathrm{NO}$ at the early stage of sepsis-induced ALI has reduced pulmonary leukocyte infiltrate and produced less oxidant injury ${ }^{12}$. If these effects are clinically significant, early and continued therapy with inhaled NO could reduce the severity of some forms of lung injury.

By contrast, activated neutrophils can convert nitrite, a major end-product of NO metabolism, into nitryl chloride and nitrogen dioxide, which can stimulate oxidative reaction during inflammation ${ }^{13)}$. Moreover, nitric oxide pretreatment aggravated ALI in an isolated rabbit lung model of oleic acid-induced acute lung injury ${ }^{14)}$. These disparate effects could be related to differences in the timing of administration, and/or in the concentration of inhaled NO species, or to model differences.

One of the mechanisms by which NO may modulate lung inflammation is possible through interaction with the transcriptional regulatory factor nuclear factor kappa B (NF- $\kappa$ B), which plays a central role in regulating the transcription of many inflammatory cytokines, adhesion molecules, and other mediators involved in ALI. Recent studies indicate that intraperitoneal administration of endotoxin to rats can lead to activation of NF- $\kappa \mathrm{B}$ in lung tissue, which is associated with lung neutrophilia, increased epithelial permeability, and lipid peroxidation ${ }^{15}$. In vivo activation of $\mathrm{NF}-\kappa \mathrm{B}$, but no other transcription factors, in alveolar macrophages from ARDS patients has also been demonstrated ${ }^{16)}$. Moreover, the gene expression of the inducible NOS isoform seems to be controlled by the $\mathrm{NF}-\kappa \mathrm{B}$ in part ${ }^{17)}$. We investigated the effects of inhaled NO on the inflammatory response and the NF- $\kappa \mathrm{B}$ activation during lipopolysaccharide (LPS)-induced acute lung injury in rabbits ${ }^{18), 19}$. We found that LPS treated rabbits with $10 \mathrm{ppm}$ of NO inhalation (LPSNO) for $6 \mathrm{hr}$ showed the attenuation of ALI induced by LPS reflected by decreased neutrophil number and the concentration of $\mathrm{LDH}$ and protein in bronchoalveolar lavaged fluid (Fig. 1). The ROS activity in resting and phorbol 12-myristate 13-acetate (PMA)- or zymosanstimulated cells from LPS-NO animals had decreased by 47,71 , and 79 percent, respectively, compared to LPS animals (Fig. 2). The production of interleukin (IL)$1 \beta$ and IL-8 proinflammatory cytokines in alveolar macrophages at rest and stimulation with PMA or zymosan had also diminished among LPS-NO animals. The DNA-binding activity of NF- $\kappa \mathrm{B}$ in alveolar macrophages from LPS animals was increased at rest and stimulation with one of these stimulants compared to saline controls, whereas these activities were also blocked in LPS-NO animals (Fig. 3). The molecular mechanisms, how NO down-regulates LPS-induced $\mathrm{NF}-\kappa \mathrm{B}$ activation, have not been resolved. ROS are involved in the signal transduction associated with $\mathrm{NF}-\kappa \mathrm{B}$ activation. In our study, inhaled NO had weakened the activities of ROS as well as of NF- $\kappa \mathrm{B}$. This result suggests that inhaled NO may affect a still undetermined membrane component required for the activation of nicotinamide adenine dinucleotide phosphate (NADPH) oxidase, which produces the oxidative burst in macrophages or neutrophils ${ }^{10}$, and simultaneously 

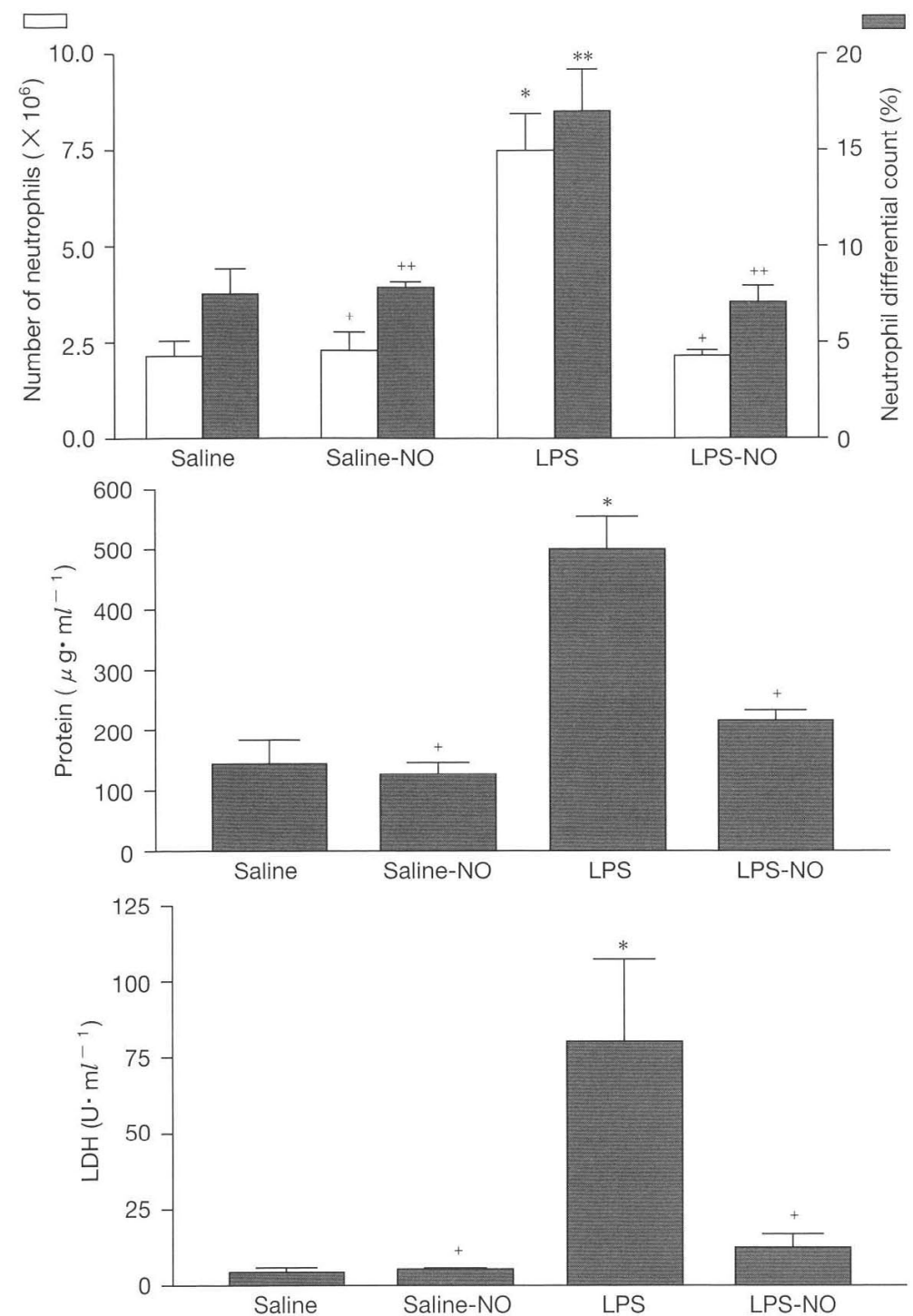

Fig. 1 Neutrophil number with its differential count $(\%)$ and the concentration of protein and lactic dehydrogenase (LDH) in bronchoalveolar lavage fluid. Saline (30 $\mathrm{ml}$ at a time) was slowly injected into the endotracheal tube of the rabbits'excised lung and then withdrawn until recovered volume reached $150 \mathrm{~m} l$ to retrieve neutrophils from the alveolar spaces. The groups represent rabbits treated as follows: Saline, saline-iv; Saline-NO, saline (iv)-NO inhalation; LPS, LPS (iv): LPS-NO, LPS (iv)-NO inhalation. Values represent mean \pm SD. *\&** Significant difference compared with saline $(P<0.05)$, and ${ }^{+} \&^{++}$significant differences compared with LPS group $(P<0.05)$. NO, nitric oxide; LPS, lipopolysaccharide.

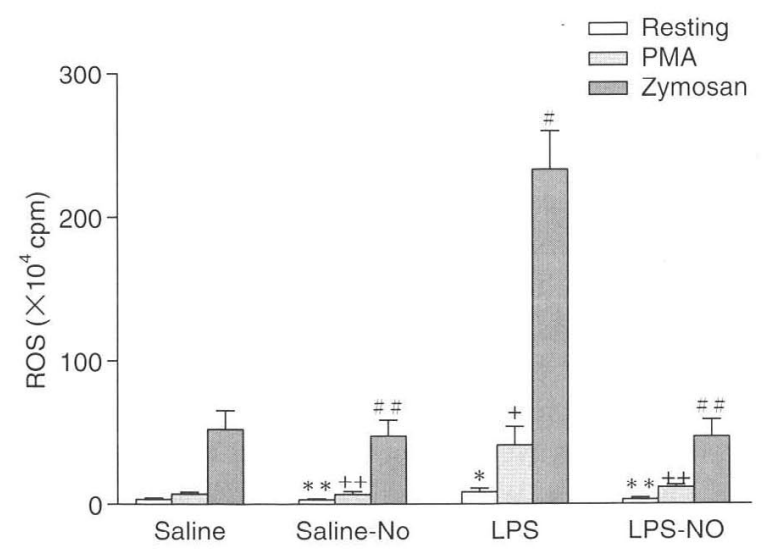

Fig. 2 Results of chemiluminescence assays performed to determine the reactive oxygen species (ROS)-secreting activity of cells obtained from the BAL fluid after $6 \mathrm{hr}$ inhalation of nitric oxide with $10 \mathrm{ppm}$. ROS activity was measured at rest, and following the stimulation of BAL cells $\left(1.5 \times 10^{6}\right.$ alveolar macrophages $/ 0.75 \mathrm{~m} l$ HEPES $)$ with either PMA $(3 \mu \mathrm{M})$ or zymosan $\left(2 \mathrm{mg} \cdot \mathrm{ml}^{-1}\right)$. Chemiluminescence was significantly increased in the resting, and PMA- and zymosan-stimulated cells of LPS-treated animals, compared with saline controls $\left(P^{*},{ }^{+},{ }^{\#}<0.05\right)$. The ROS activity in BAL cells of LPS-NO animals, at rest and stimulated with PMA or zymosan was significantly decreased compared with the values in LPStreated animals $\left(P^{* *},{ }^{++}, \# \#<0.05\right)$. NO, nitric oxide; LPS, lipopolysaccharide; PMA, phorbol 12-myristate 13-acetate; BAL, bronchoalveolar lavage. 


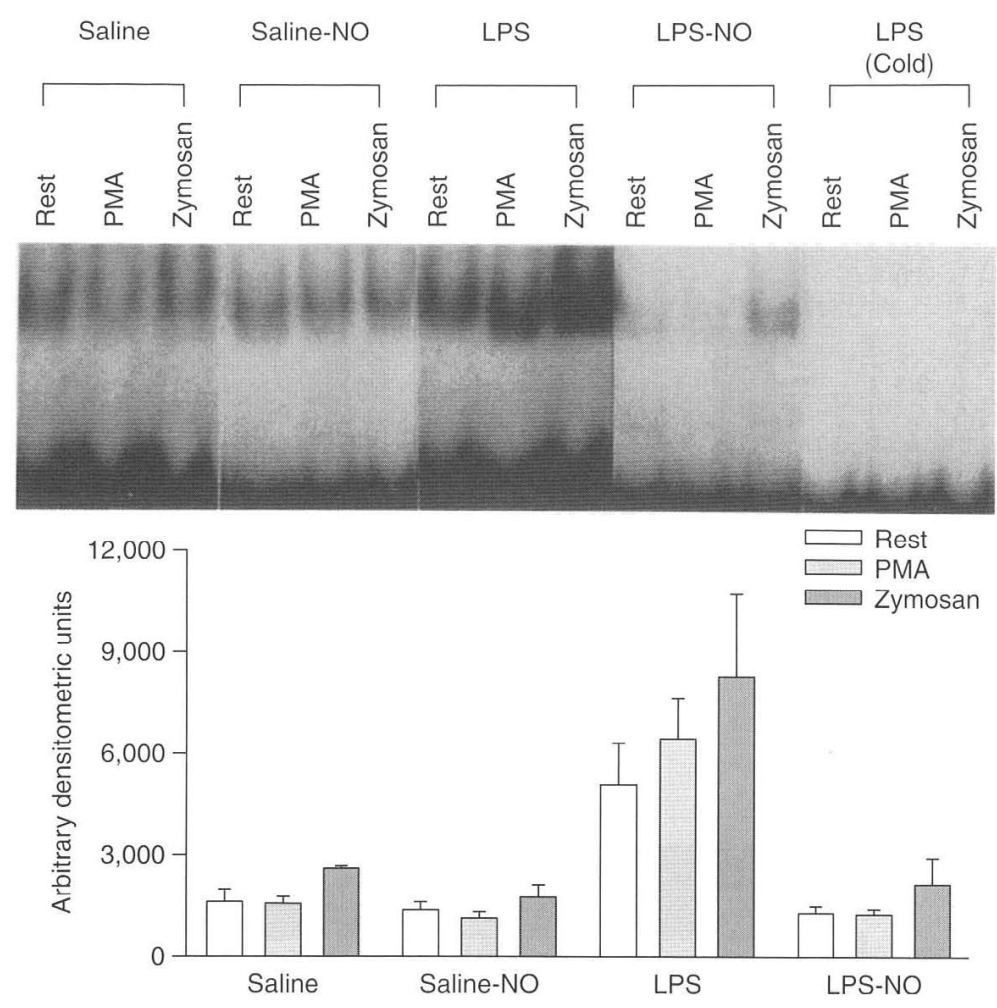

Fig. 3 Electrophoretic mobility shift assay (EMSA) illustrating the DNA-binding activity of NF- $\kappa$ B to the NF- $\kappa$ B motif. The group represents a rabbit treated as follows: Saline, saline-iv: Saline-NO, saline (iv)-NO inhalation; LPS, LPS (iv); LPS-NO, LPS (iv)-NO inhalation. Nuclear extracts were prepared in alveolar macrophages $\left(5 \times 10^{6}\right.$ alveolar macrophages), at rest and stimulated with either PMA $(3 \mu \mathrm{M})$ or zymosan $\left(2 \mathrm{mg} \cdot \mathrm{m} l^{-1}\right)$. To prove that the band in the EMSA represents specific binding of protein with p32 labeled double-stranded DNA, containing NF- $\kappa$ B consensus sequence, high concentration of double-stranded DNA without p32 labeling (cold) was added to the reaction mixture, containing nuclear extract protein and p32 labeled double-stranded DNA for the competition between unlabeled probe and labeled probe. In lanes 13, 14, and 15, the addition of $100 \mathrm{ng}{ }^{32}$-P-unlabeled cold competitor to the LPS samples (LPS cold, resting, PMA-treated, and zymosan-treated, respectively) successfully competed for NF- $\kappa \mathrm{B}$ binding, and eliminated the specific band. NO, nitric oxide; LPS, lipopolysaccharide; PMA, phorbol 12-myristate 13acetate; NF- $\kappa$ B, nuclear factor kappa B.

blocks the signal pathways initiated by ROS. NO may also inhibit NF- $\kappa$ B directly, through S-nitrosylation of the p50 subunit ${ }^{20)}$. Peng et $\mathrm{al}^{21)}$ reported that $\mathrm{NO}$ inhibits LPS-induced NF- $k \mathrm{~B}$ activation in a murine macrophage cell line, via its effect on the transcription and stability of the NF- $\kappa \mathrm{B}$ inhibitory protein, I $\kappa \mathrm{B} a$. This effect is independent of guanylate cyclase. This independence of guanylate cyclase has been also exemplified in inhibiting $\mathrm{NF}-\kappa \mathrm{B}$ activation by $\mathrm{NO}^{22}$, and in reducing endothelial cell expression of vascular cell adhesion molccule-1 (VCAM-1) by NO23). Alternatively. NO may interact directly with the intracellular signaling pathways leading to NF- $\kappa \mathrm{B}$ activation, even though NO target molecules have not been identified. Similar inhibitory effects of inhaled NO on neutrophil transmigration and ROS activity have been reported in neutrophils from the bronchoalveolar lavage (BAL) fluid of ARDS patients ${ }^{11)}$ and in an LPS-induced ALI animal mode ${ }^{24}$. In contrast, inhaled NO did not alter interleukin-8, elastase, and myeloperoxidase concentration in BAL fluid in ARDS patients ${ }^{25}$. Moreover, leukotriene $\mathrm{B}_{4}$, and $\mathrm{C}_{4} \mathrm{D}_{4} \mathrm{E}_{4}$ was significantly elevated at $72 \mathrm{hr}$ of NO inhalation compared with control group in the patients ${ }^{25}$.

Concentrations of nitrite and nitrate in BAL fluid and blood have increased in a model of LPS-induced $\mathrm{ALI}^{26)}$. Rabbits treated with aminoguanidine, a selective inhibitor of NNOS $^{27}$, or mice deficient in the iNOS gene $^{28)}$ are resistant to LPS-induced ALI. These observations suggest that overproduction of NO may contribute to the inflammatory process associated with ALI. Inhaled NO inhibits constitutive and inducible NOS activity in various tissues and cells, including endothelial cells and alveolar macrophages in vitro. Griscavage et al. ${ }^{29)}$ reported the role of NO as a negative feedback modulator of iNOS by interacting with enzyme-bound heme, which may play a role in catalysis by serving as the terminal electron acceptor in the oxygenation of L-arginine to the intermediate $\mathrm{N}^{\mathrm{G}}$-hydroxy-L-arginine. However, the effect of inhaled NO on endogenous NO production in ALI has not been fully elucidated. We investigated the role of inhaled $\mathrm{NO}$ in intrapulmonary production of NO and ALI after LPS treatment on rabbits. LPS infusion had in- 
Table 1 Nitric oxide (NO) levels in alveolar macrophage ${ }^{+}$culture $^{18)}$

\begin{tabular}{|c|c|c|c|c|}
\hline \multirow[b]{2}{*}{ Stimulant } & \multicolumn{4}{|c|}{ Animal Groups ${ }^{++}$} \\
\hline & Salir & Saline-NO $(\mu \mathrm{M})$ & LPS $(\mu \mathrm{M})$ & \\
\hline $\mathrm{R}$ & 8) & $69 \sim 2.27)$ & $2.72(2.03 \sim 3.60)$ & 0.5 \\
\hline PMA & 9) & $48 \sim 2.09)$ & $2.92(2.29 \sim 5.07)^{b}$ & $.21)^{c}$ \\
\hline & $94-7$ & $2 \sim 1.77)$ & 3.13 & \\
\hline \multicolumn{5}{|c|}{$\begin{array}{l}\text { LPS, lipopolysaccharide. }{ }^{+} \text {Aliquots of } 1 \mathrm{~m} l \text {, containing } 10^{6} \text { alveolar macrophages, were added to } \\
24 \text {-well plates. }{ }^{++} \text {The groups represent rabbits treated as follows: saline, saline-iv; saline-NO } \\
\text { saline (iv)-NO inhalation; LPS, LPS (iv); LPS-NO, LPS (iv)-NO inhalation. NO levels were mea } \\
\text { sured in the supernatants of bronchoalveolar lavage fluid and alveolar macrophages cultured a } \\
\text { rest and stimulation with either phorbol } 12 \text {-myristate } 13 \text {-acetate (PMA, } 3 \times 10^{-6} \mathrm{M} \text { ) or zymo } \\
\text { san }\left(2 \mathrm{mg} \cdot \mathrm{m} l^{-1}\right) \text { for } 24 \mathrm{hrs} \text { using nitrite assay. Values represent median with range. Five } \\
\text { rabbits in each group except LPS-NO ( }=3 \text { ); }{ }^{b} P<0.05 \text { between LPS and saline group; }{ }^{c} P<0.05 \\
\text { between LPS-NO and LPS group. PMA, phorbol } 12 \text {-myristate } 13 \text {-acetate. }\end{array}$} \\
\hline
\end{tabular}

creased the levels of NO in BAL fluid by 3.1 fold and in the alveolar macrophages at resting state and stimulation with either PMA or zymosan by 2.3, 2.1, and 1.7 fold, respectively, compared to those values of saline controls ${ }^{18)}$. Inhaled NO resulted in decreases in NO levels in BAL fluid by $57 \%$ and in the alveolar macrophages at rest and stimulation either PMA or zymosan by 50,66 , and $45 \%$, respectively, accompanied by declines in the lung injurious parameters as to our rabbit model (Table 1$)^{18)}$. These findings support the hypothesis that $\mathrm{NO}$ over-production may contribute to the pathogenesis of ALI, and that inhaled NO may have a beneficial therapeutic effect on this setting. The effect of inhaled NO on NO production is supported by the results of Honda et al.30) where inhaled NO is reported to reduce tyrosine nitration in the lung tissue of rats treated with LPS. By contrast, Meldrum et $\mathrm{al}^{31)}$ have reported that $\mathrm{L}$-arginine decreased the production of alveolar macrophage proinflammatory cytokines during LPS-induced ALI by an NO synthasedependent mechanism, suggesting that augmenting local NO production may reduce inflammation during ALI. Furthermore, Walley et $\mathrm{al}^{22)}$ reported that LNAME, an NO synthase inhibitor, increases tumor necrosis factor (TNF)- $a$ and IL- 6 protein and mRNA expression in lung homogenate samples obtained from mice after intratracheal injection with endotoxin. These authors also reported that, in addition to the in vivo model, exogenous or endogenous NO down-regulates inflammatory cytokine production in lung macrophages in vitro. These results suggest that the effect of nitric oxide on the pathogenesis of endotoxin-induced acute lung injury may depend on the local concentration of NO.

\section{Potential benefits by low dose NO inhala- tion in ALI patients}

It is obvious that $\mathrm{NO}$ is not a single molecule to mediate the complicated inflammatory cascade observed in ALI. However, experimental and clinical evidences suggest that NO is an important inflammatory modulator for ALI. Overproduction of NO may lead to oxidative lung damage increasing vascular permeability. Inhaled NO could inhibit constitutive and inducible NOS activity or increase NO concentration in lung according to the concentration of NO inhalation. Depending on the local NO milieu, oxidative burst of activated neutrophils and alveolar macrophage could be changed leading to the alteration of NF- $\kappa$ B activity in the inflammatory cells (Fig. 4, 5). Inhaled NO inhibited platelet-leukocyte interactions by the inhibition in platelet P-selectin expression among ARDS patients ${ }^{32}$. Neutrophils appear to play a crucial role in developing ALI. It is reported that early alterations in -neutrophil activation is likely to be associated with patient outcome in $\mathrm{ALI}^{33}$. When considering the inhaled NO's role for neutrophils' transmigration into lung and their functional modulation, early initiation of NO inhalation might be beneficial to modulate the pathogenesis of ALI leading to better results. The timing and dose of $\mathrm{NO}$ inhalation should be elucidated to address the above question. On the contrary, modest inflammatory response is mandatory for optimal host defense mechanisms. Therefore, any measure to attenuate an inflammatory reaction, including NO inhalation, must weigh the balance between suppression and maintenance of its inflammatory response before therapeutic trials.

\section{Conclusion}

Trials to attenuate the inflammatory process in ALI have not improved the outcome of ARDS patients. The only positive study on ARDS patients' outcome is low tidal volume ventilation strategy. However, the antiinflammatory strategy targeting the transcriptional regulatory proteins deemed to be promising in ALI. The NO inhalation, as more than a selective vasodilator, may attenuate ALI by reducing abilities of pulmonary inflammatory cells to produce ROS and proinflammatory cytokines via the inhibition of NF- $\kappa \mathrm{B}$ activation and by suppressing endogenous NO production, suggest- 


\section{Inhaled NO}

$\downarrow$

Inhibit constitutive \& inducible NOS activity

\&/or may increase NO concentration in the lung in high dose of iNO

$\begin{array}{ll}\begin{array}{l}\text { Oxidative burst in macrophages \& } \\ \text { PMNs }(\downarrow)+\text { blocking signal pathways } \\ \text { initiated by ROS }\end{array} & \begin{array}{l}\text { Abolition of endogenous NO's role to } \\ \text { modulate inflammation, or Synthesis of }\end{array} \\ \text { Peroxynitrite }\end{array}$

Inhibit NF- $\kappa$ B directly through Snitrosylation of the p50 subunit or

Prevent decrease in the levels of $\mathrm{I} \kappa \mathrm{B}-\alpha$ in alveolar macrophages modulate inflammation, or Synthesis of

Fig. 4 The effect of nitric oxide on the pathogenesis of endotoxin-induced acute lung injury might be dependent on the local concentration of NO. NO, nitric oxide; NOS, NO sybthase; iNO, inhaled NO; ROS, reactive oxygen species; $\mathrm{NF}-\kappa \mathrm{B}$, nuclear factor kappa B.
Attenuate/exacerbate lung injury depending on the local NO concentration

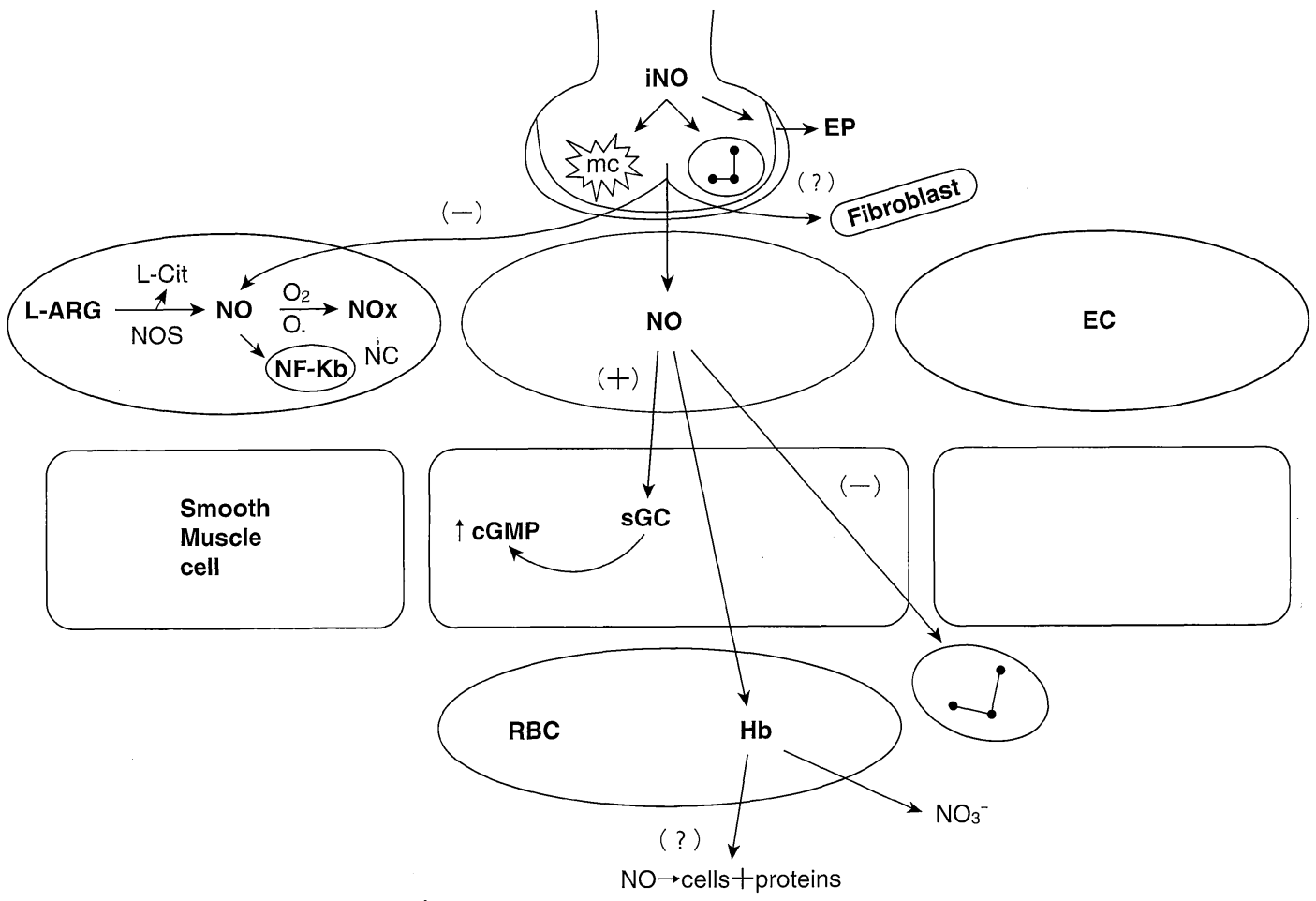

Fig. 5 Inhaled NO as an anti-inflammatory molecule.

iNO, NO inhalation; EP, epithelial cell; EC, endothelial cell; mc, macrophage; ARG, arginine; NOS, nitric oxide synthase; Cit, citrulline; NC, nucleous; sGC, soluble guanyl cyclase; RBC, red blood cell; Hb, hemoglobin; $\odot$, neutrophil; +, augmentation; - , inhibition.

ing a potential antiinflammatory measure for these patients. Beneficial effects on oxygenation of inhaled NO turn out to be less than $5 \mathrm{ppm}$. Therefore, early initiation of NO inhalation with lower dose may be a more reasonable approach to patients with ALI, if indicated. In addition, the effect of early and continued therapy with low dose of inhaled NO on ALI is deserving of further examination.

\section{References}

1) Nathan C, Xie QW. Regulation of biosynthesis of nitric oxide. J Biol Chem. 1994;269:13725-8.

2) Raychaudhuri B, Dweik R, Connors MJ, et al. Nitric oxide blocks nuclear factor-kappaB activation in alveolar macrophages. Am J Respir Cell Mol Biol. 1999;21:311-6.

3) Bernareggi M, Mitchell JA, Barnes PJ, et al. Dual action of nitric oxide on airway plasma leakage. Am J Respir Crit Care Med. 
1997;155:869-74

4) Frostell C, Fratacci MD, Wain JC, et al. Inhaled nitric oxide. A selective pulmonary vasodilator reversing hypoxic pulmonary vasoconstriction [published erratum appears in Circulation. 1991 Nov;84(5):2212]. Circulation. 1991;83:2038-47.

5) Gerlach H, Rossaint R, Pappert D, et al. Time-course and doseresponse of nitric oxide inhalation for systemic oxygenation and pulmonary hypertension in patients with adult respiratory distress syndrome [see comments]. Eur J Clin Invest. 1993;23:499-502.

6) Puybasset L, Rouby JJ, Mourgeon E, et al. Factors influencing cardiopulmonary effects of inhaled nitric oxide in acute respiratory failure. Am J Respir Crit Care Med. 1995;152:318-28.

7) Koh Y, Lee KM, Lim CM, et al. The combined therapy of inhaled nitric oxide and prone positioning has an additive effect on gas exchange and oxygen transport in patients with acute respiratory distress syndrome. Crit Care Shock. 1998;1:117-24.

8) Dellinger RP, Zimmerman JL, Taylor RW, et al. Effects of inhaled nitric oxide in patients with acute respiratory distress syndrome: results of a randomized phase II trial. Inhaled Nitric Oxide in ARDS Study Group. [see comment]. Crit Care Med. 1998;26:15-23.

9) Clark RH, Kueser TJ, Walker MW, et al. Low-dose nitric oxide therapy for persistent pulmonary hypertension of the newborn. Clinical Inhaled Nitric Oxide Research Group. N Engl J Med. 2000;342:469-74.

10) Clancy RM, Leszczynska-Piziak J, Abramson SB. Nitric oxide, an endothelial cell relaxation factor, inhibits neutrophil superoxide anion production via a direct action on the NADPH oxidase. J Clin Invest. 1992;90:1116-21.

11) Chollet-Martin S, Gatecel C, Kermarrec N, et al. Alveolar neutrophil functions and cytokine levels in patients with the adult respiratory distress syndrome during nitric oxide inhalation. Am J Respir Crit Care Med. 1996;153:985-90.

12) Razavi HM, Werhun R, Scott JA, et al. Effects of inhaled nitric oxide in a mouse model of sepsis-induced acute lung injury. Crit Care Med. 2002;30:868-73.

13) Eiserich JP, Hristova M, Cross CE, et al. Formation of nitric oxidederived inflammatory oxidants by myeloperoxidase in neutrophils. Nature. 1998;391:393-7.

14) Rayhrer CS, Edmisten TD, Cephas GA, et al. Nitric oxide potentiates acute lung injury in an isolated rabbit lung model. Ann Thorac Surg. 1998;65:935-8.

15) Blackwell TS, Blackwell TR, Holden EP, et al. In vivo antioxidant treatment suppresses nuclear factor-kappa B activation and neutrophilic lung inflammation. J Immunol. 1996;157:1630-7.

16) Schwartz MD, Moore EE, Moore FA, et al. Nuclear factor-kappa $B$ is activated in alveolar macrophages from patients with acute respiratory distress syndrome. Crit Care Med. 1996;24:1285-92.

17) Xie QW, Kashiwabara $Y$, Nathan C. Role of transcription factor NF-kappa B/Rel in induction of nitric oxide synthase.J Biol Chem. 1994:269:4705-8.
18) Koh Y, Kang JL, Park W, et al. Inhaled nitric oxide down-regulates intrapulmonary nitric oxide production in lipopolysaccharide-induced acute lung injury. Crit Care Med. 2001;29:1169-74.

19) Kang JL, Park W, Pack IS, et al. Inhaled nitric oxide attenuates acute lung injury via inhibition of nuclear factor-kappa $B$ and inflammation. J Appl Physiol. 2002;92:795-801.

20) DelaTorre A, Schroeder RA, Kuo PC. Alteration of NF-kappa B p50 DNA binding kinetics by S-nitrosylation. Biochem Biophys Res Commun. 1997;238:703-6.

21) Peng HB, Rajavashisth TB, Libby P, et al. Nitric oxide inhibits macrophage-colony stimulating factor gene transcription in vascular endothelial cells. J Biol Chem. 1995;270: 17050-5.

22) Walley KR, McDonald TE, Higashimoto Y, et al. Modulation of proinflammatory cytokines by nitric oxide in murine acute lung injury. Am J Respir Crit Care Med. 1999;160:698-704.

23) De Caterina R, Libby P, Peng HB, et al. Nitric oxide decreases cytokine-induced endothelial activation. Nitric oxide selectively reduces endothelial expression of adhesion molecules and proinflammatory cytokines. J Clin Invest. 1995;96:60-8.

24) Bloomfield GL, Holloway S, Ridings PC, et al. Pretreatment with inhaled nitric oxide inhibits neutrophil migration and oxidative activity resulting in attenuated sepsis-induced acute lung injury [see comments]. Crit Care Med. 1997;25:584-93.

25) Cuthbertson BH, Galley HF, Webster NR. Effect of inhaled nitric oxide on key mediators of the inflammatory response in patients with acute lung injury. Crit Care Med. 2000;28:1736-41.

26) Matsuo $\mathrm{N}$. The role of intrapulmonary nitric oxide generation in the development of adult respiratory distress syndrome. Surg Today. 1999;29:1068-74.

27) Mikawa K, Nishina K, Tamada M, et al. Aminoguanidine attenuates endotoxin-induced acute lung injury in rabbits. Crit Care Med. 1998:26:905-11.

28) Kristof AS, Goldberg P, Laubach V, et al. Role of inducible nitric oxide synthase in endotoxin-induced acute lung injury. Am J Respir Crit Care Med. 1998;158:1883-9.

29) Griscavage JM, Rogers NE, Sherman MP, et al. Inducible nitric oxide synthase from a rat alveolar macrophage cell line is inhibited by nitric oxide. J Immunol. 1993;151:6329-37.

30) Honda K, Kobayashi H, Hataishi R, et al. Inhaled nitric oxide reduces tyrosine nitration after lipopolysaccharide instillation into lungs of rats. Am J Respir Crit Care Med. 1999;160:678-88.

31) Meldrum DR, McIntyre RC, Sheridan BC, et al. L-arginine decreases alveolar macrophage proinflammatory monokine production during acute lung injury by a nitric oxide synthase-dependent mechanism. J Trauma. 1997;43:888-93.

32) Gries A, Herr A, Kirsch S, et al. Inhaled nitric oxide inhibits platelet-leukocyte interactions in patients with acute respiratory distress syndrome. Crit Care Med. 2003;31:1697-704.

33) Yang KY, Arcaroli JJ, Abraham E. Early alterations in neutrophil activation are associated with outcome in acute lung injury. Am J Respir Crit Care Med. 2003;167:1567-74. 